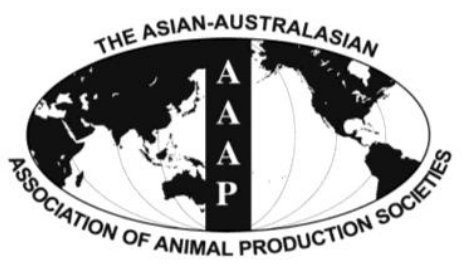

Asian-Aust. J. Anim. Sci.

Vol. 26, No. 3 : 433-442 March 2013

http://dx.doi.org/10.5713/ajas.2011.11515

www.ajas.info

ISSN 1011-2367 ISSN 1976-5517

\title{
Dynamics of Air Temperature, Velocity and Ammonia Emissions in Enclosed and Conventional Pig Housing Systems
}

\author{
J. I. Song, K.-H. Park, J. H. Jeon, H. L. Choi ${ }^{1}$ and A. J. Barroga ${ }^{2}$,* \\ National Livestock Research Institute, Rural Development Administration, Suwon, 441-350, Korea
}

\begin{abstract}
This study aimed to compare the dynamics of air temperature and velocity under two different ventilation and housing systems during summer and winter in Korea. The $\mathrm{NH}_{3}$ concentration of both housing systems was also investigated in relation to the pig's growth. The ventilation systems used were; negative pressure type for the enclosed pig house (EPH) and natural airflow for the conventional pig house $(\mathrm{CPH})$. Against a highly fluctuating outdoor temperature, the EPH was able to maintain a stable temperature at 24.8 to $29.1^{\circ} \mathrm{C}$ during summer and 17.9 to $23.1^{\circ} \mathrm{C}$ during winter whilst the $\mathrm{CPH}$ had a wider temperature variance during summer at 24.7 to $32.3^{\circ} \mathrm{C}$. However, the temperature fluctuation of the $\mathrm{CPH}$ during winter was almost the same with that of $\mathrm{EPH}$ at 14.5 to $18.2^{\circ} \mathrm{C}$. The $\mathrm{NH}_{3}$ levels in the $\mathrm{CPH}$ ranged from 9.31 to $16.9 \mathrm{mg} / \mathrm{L}$ during summer and 5.1 to $19.7 \mathrm{mg} / \mathrm{L}$ during winter whilst that of the EPH pig house was 7.9 to $16.1 \mathrm{mg} / \mathrm{L}$ and 3.7 to $9.6 \mathrm{mg} / \mathrm{L}$ during summer and winter, respectively. These values were less than the critical ammonia level for pigs with the EPH maintaining a lower level than the CPH in both winter and summer. The air velocity at pig nose level in the EPH during summer was $0.23 \mathrm{~m} / \mathrm{s}$, enough to provide comfort because of the unique design of the inlet feature. However, no air movement was observed in almost all the lower portions of the CPH during winter because of the absence of an inlet feature. There was a significant improvement in weight gain and feed intake of pigs reared in the EPH compared to the CPH (p<0.05). These findings proved that despite the difference in the housing systems, a stable indoor temperature was necessary to minimize the impact of an avoidable and highly fluctuating outdoor temperature. The EPH consistently maintained an effective indoor airspeed irrespective of season; however the CPH had defective and stagnant air at pig nose level during winter. Characteristics of airflow direction and pattern were consistent relative to housing system during both summer and winter but not of airspeed. The ideal air velocity measurement favored the EPH and therefore can be appropriate for the Korean environment. Further emphasis on its cost effectiveness will be the subject of future investigations. (Key Words: Conventional Pig Housing, Enclosed Pig Housing, Ammonia, Hydrogen Sulfide, Air Velocity)
\end{abstract}

\section{INTRODUCTION}

The unique weather conditions in Korea, that of an extremely cold winter and a very humid summer had resulted to the proliferation of conventional pig housing systems without appropriate ventilation systems designed to give comfort and consequently enhanced growth performance of pigs. Schauberger et al. (2000) stated that the physical environment of farm animals inside buildings is primarily characterized by hygro-thermal parameters and air quality. These parameters are influenced by the

\footnotetext{
* Corresponding Author: Antonio J. Barroga. Tel: +63-44-456

5164, Fax: +63-44-456-0107, E-mail: antonio_barroga@yahoo.com

${ }^{1}$ Department of Food and Animal Biotechnology, Seoul National University, Seoul, 151-921, Korea.

${ }^{2}$ Department of Animal Science, Central Luzon State University, Science City of Munoz, Nueva Ecija, 3120, Philippines.

Submitted Dec. 27, 2011; Accepted Mar. 24, 2012; Revised Nov. 16, 2012
}

interaction of outdoor temperature, livestock, ventilation system and building design. Several workers proved that proper ventilation can also improve air quality inside pig buildings (Brugger et al., 1977; Esmay, 1978; Curtis, 1983; Chiang and Hsia, 2005). Way back in the mid 60's, Bond et al. (1965) had already emphasized the importance of air velocities on heat and moisture loss on growth of pigs. A 60 to $70 \mathrm{~kg}$ pig could maintain a heat loss balance in a $10^{\circ} \mathrm{C}$ and $20^{\circ} \mathrm{C}$ environment even if the air velocity was raised from $0.2 \mathrm{~m} / \mathrm{s}$ to $0.8 \mathrm{~m} / \mathrm{s}$. A pig of 40 to $170 \mathrm{~kg}$ exposed to an air velocity of $0.2 \mathrm{~m} / \mathrm{s}$ to $1.5 \mathrm{~m} / \mathrm{s}$ can increase its need for feed per unit weight but its weight gain is compromised. However, even if pigs are raised at higher temperature between $35^{\circ} \mathrm{C}$ to $38^{\circ} \mathrm{C}$, as long as air velocity is increased, satisfactory weight gain is still expected.

Esmay (1978) distinguished the ventilation system of pig houses into natural and machine-operated ones. Pig houses with natural ventilation systems were required to be 


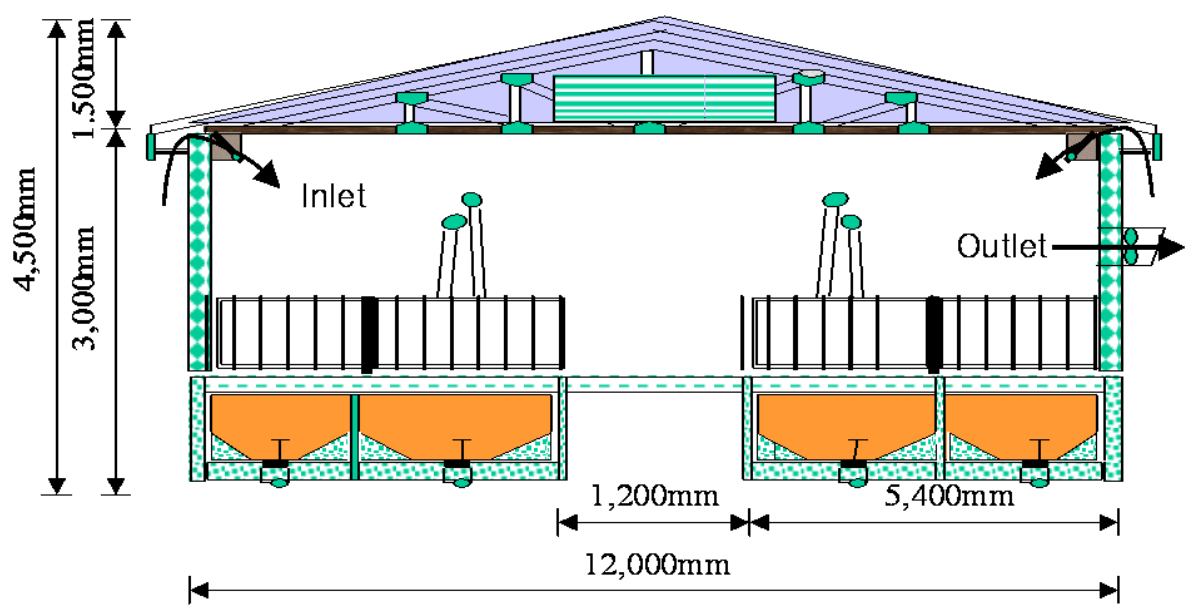

Figure 1. Dimension and schematic of airflow via location of inlet of EPH.

large enough to accommodate the animals' body heat emissions and solar heat. For each $\mathrm{m}^{2}$ floor space, a 0.2 $\mathrm{m}^{3} / \mathrm{s}$ ridge opening was recommended. For mechanical ventilation systems, MWPS 32 (1990) reported that methods of airflow were dependent on the width of the house.

The concept of enclosed growing-finishing pig house was introduced in Korea in the 1990s. Since then, innovative pig farmers adopted environment control facilities and automation especially in large scale operations. However, no in-depth comparison of conventional and enclosed growing-finishing pig houses has been done yet. The only study concerning Korea's pig house facilities dealt on pig house structures and environment was conducted by Choi et al. (2000). Although Yoo et al. (1998) did publish a study of Korea's pig house model, it was limited to EPH. Therefore, this study compared and analyzed the efficiency of Korea's existing $\mathrm{CPH}$ and EPH and also characterized their environmental related efficiencies like air temperature, air velocity and $\mathrm{NH}_{3}$ emission and their effect on pig performance.

\section{MATERIALS AND METHODS}

\section{Experimental site and duration}

The site of the experimental houses namely; the enclosed pig housing system (EPH) and the conventional pig housing system $(\mathrm{CPH})$ were also constructed in the University Animal Farm of the College of Agriculture \& Life Science at Seoul National University. The duration for data gathering of the experimental houses was from winter to summer.

\section{Description of the housing systems}

The airflow of the EPH was through a planar slot with the exhaust fan installed in the side wall whilst that of the $\mathrm{CPH}$ was made possible by a 1 foot air fan $(\Phi 50 \mathrm{~cm})$ (Figure 1, Table 1). A unique feature of the slot inlet designed by the senior author and with approved Korean patent is the installation of an adjustable insulated baffle with a partition that can be opened to accommodate winter air while preventing the inflow of summer air and vice versa. The ventilation in the EPH adopted the enforced method using negative pressure on the fan as compared to the natural method for the CPH. In Figure 2, the location of the airflow inlet which is indicated by an inward arrow is above the winch curtain. The airflow rate of the air fan in the EPH was automatically controlled to 5 stages with a $95 \%$ maximum operating capacity during summer and a minimum of $5 \%$ during winter.

The total area of the EPH was $12 \mathrm{~m}(\mathrm{~W}) \times 20 \mathrm{~m}(\mathrm{~L})$, with the internal stalls having a dimension of $2.1 \mathrm{~m} \times 5.6 \mathrm{~m}$ as specified by MWPS 32 (1988). There were 18 pens in the $\mathrm{EPH}$, with 9 pens on both sides and a center alley

Table 1. Specifications of measuring instruments

\begin{tabular}{|c|c|c|c|}
\hline \multicolumn{2}{|c|}{ Environmental factors } & Model & Specification \\
\hline \multicolumn{2}{|c|}{ Temperature $^{1} \pm 0.5 \mathrm{~m} / \mathrm{s}$} & NEC 3500 & 64 channels \\
\hline \multicolumn{2}{|c|}{ Air speed $(\text { recoder })^{2} \pm 0.05 \mathrm{~m} / \mathrm{s}$} & Kanomax 6242 & 64 channels \\
\hline \multicolumn{2}{|c|}{ Air speed ${ }^{3} \pm 0.02 \mathrm{~m} / \mathrm{s}$} & Solomat 510e, Kanomax 6112 & 0 to $12 \mathrm{~m} / \mathrm{s}, 0$ to $50 \mathrm{~m} / \mathrm{s}$ \\
\hline \multicolumn{2}{|c|}{ Gas $\left(\mathrm{NH}_{3}\right)$} & Gastec & 0 to $30 \mathrm{mg} / \mathrm{L}$ \\
\hline \multirow[t]{2}{*}{ Ventilation fan } & (Side wall) & EMI $Ф 500$ & 5,580 to $8,510 \mathrm{~m}^{3} / \mathrm{h}$ \\
\hline & (Pit fan) & $\Phi 500$ & $5,350 \mathrm{~m}^{3} / \mathrm{h}$ \\
\hline
\end{tabular}

\footnotetext{
$1,2,3$ Accuracy.
} 


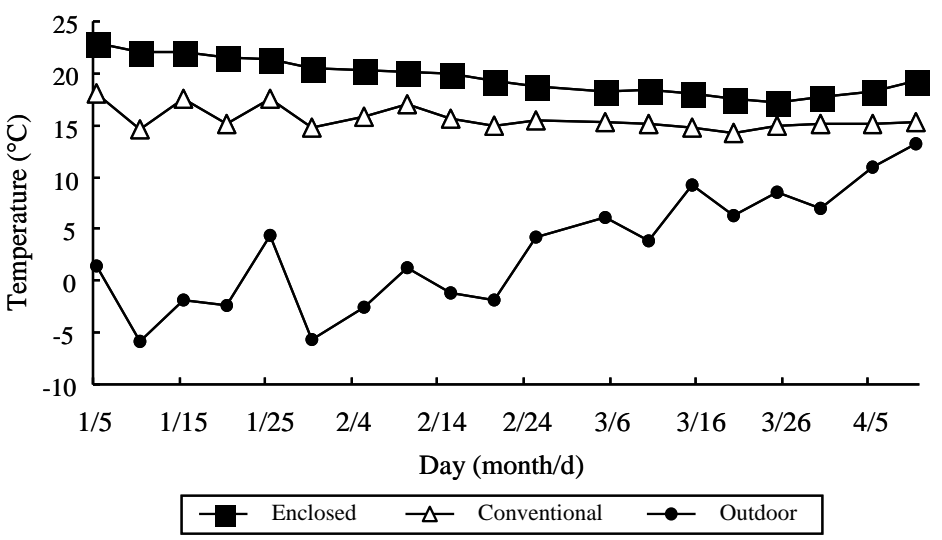

Figure 2. Periodic changes of air temperature of the $\mathrm{EPH}, \mathrm{CPH}$ and the outdoor temperature during winter.

measuring $1.2 \mathrm{~m}$. On the other hand, the $\mathrm{CPH}$ has a total area of $5 \mathrm{~m}(\mathrm{~W}) \times 10.0 \mathrm{~m}(\mathrm{~L})$ in size, with ten pens along on each side of the corridor and the width of the alley is $0.8 \mathrm{~m}$.

\section{Management practices of the housing systems}

Both housing systems, with 200 pigs each and an average starting weight of $26 \mathrm{~kg}$ up to $111 \mathrm{~kg}$ final weight, adopted ad libitum method of feeding and water was made accessible through a nipple drinker installed on the side wall. For the maintenance of optimal inside temperature during the winter, the EPH was provided with an individual heating lamp that could be adjusted to either $620 \mathrm{~W}$ or 310 W whilst the source of heat of the CPH was a hot blast stove. Other management protocols were based on the recommendations of the College of Agriculture and Life Sciences.

\section{Data collection method}

The measurement of the different parameters related to ventilation system and the equipment used and their specifications are summarized in Table 2.

Ventilation related parameters were measured in 27 sites of the buildings. Specifically, nine sites for measurement of air temperature and velocity were identified from each of the upper (180 $\mathrm{cm}$ above ground level), middle $(120 \mathrm{~cm}$ above ground level) and lower (30 $\mathrm{cm}$ above ground level) levels of the individual pig pens of both the EPH and CPH. These numerous sites were concentrated in the alley and individual pens on both sides to capture a very comprehensive and accurate air flow pattern in EPH and $\mathrm{CPH}$. Monitoring of air temperature and velocity were calibrated every $30 \mathrm{~min}$ and automatically stored in a computer memory.

\section{Statistical analysis}

The SAS (1991) package was used to measure data such as the air velocity and temperature and the General Linear Model was used to verify the significance of measured average values while Duncan's Multiple Range Test (DMRT) was used to determine the significance of treatment means.

\section{RESULTS AND DISCUSSION}

The ventilation method of the EPH was characterized by negative pressure and equipped with a circular duct inlet containing indoor perforated holes with the exhaust fan installed in the side wall of the piggery house. On the other hand, natural pressure was the type of ventilation method for the $\mathrm{CPH}$ with the side wall serving at the inlet and a pit type exhaust fan was installed.

Table 2. Air velocity distribution of the EPH and CPH during winter $(\mathrm{m} / \mathrm{s})$

\begin{tabular}{|c|c|c|c|c|c|c|c|c|c|}
\hline \multirow{2}{*}{ Location } & \multicolumn{3}{|c|}{ Front section } & \multicolumn{3}{|c|}{ Middle section } & \multicolumn{3}{|c|}{ Rear section } \\
\hline & Left & Alley & Right & Left & Alley & Right & Left & Alley & Right \\
\hline \multicolumn{10}{|l|}{$\overline{\mathrm{EPH}}$} \\
\hline Upper & 0.78 & 0.01 & 0.59 & 0.78 & 0.01 & 0.59 & 0.74 & 0.01 & 0.63 \\
\hline Middle & 0.21 & 0.03 & 0.25 & 0.21 & 0.03 & 0.25 & 0.26 & 0.00 & 0.32 \\
\hline Lower & 0.07 & 0.01 & 0.10 & 0.07 & 0.01 & 0.10 & 0.11 & 0.02 & 0.08 \\
\hline \multicolumn{10}{|l|}{$\mathrm{CPH}$} \\
\hline Upper & 0.05 & 0.01 & 0.09 & 0.10 & 0 & 0.12 & 0.08 & 0.01 & 0.06 \\
\hline Middle & 0.11 & 0.02 & 0.08 & 0.09 & 0.03 & 0.12 & 0.08 & 0.00 & 0.11 \\
\hline Lower & 0.00 & 0.01 & 0.00 & 0.00 & 0.01 & 0.02 & 0.01 & 0.02 & 0.02 \\
\hline
\end{tabular}

EPH Mean \pm STD: $0.26 \pm 0.08 \mathrm{~m} / \mathrm{s}$. * CPH Mean \pm STD: 0.12 $\pm 0.02 \mathrm{~m} / \mathrm{s}$. 


\section{Winter setting}

Temperature dynamics: During winter, indoor air quality is very important and this can be achieved by minimal fluctuation rate of temperature as ventilation rate is restricted. This was well demonstrated in the present study as shown by the daily air temperature dynamics in the EPH (Figure 2). The outdoor temperature during the test period ranged from 5.5 to $6.9^{\circ} \mathrm{C}$ whilst the daily indoor temperature fluctuation was $12.4^{\circ} \mathrm{C}$. This temperature difference has a great deviation when compared to the pigs tolerable daily temperature range of $4^{\circ} \mathrm{C}$. Expectedly, the pigs will have a net loss of heat to the environment. Likewise, when temperature drops more energy is needed to maintain the heat requirement of the pigs. As a result, the lower critical temperature or the temperature at which productivity of the animals is adversely affected. Harmon and Lawrence (1995) reported varying critical temperature for hogs at different weights. So to overcome this critical temperature during winter, we provided heating lamps supplying heat equivalent to $50,000 \mathrm{Kcal} / \mathrm{h}$. As a result, the $\mathrm{EPH}$ maintained a temperature fluctuation range of $15^{\circ} \mathrm{C}$ as shown in Figure 2, which was about $3^{\circ} \mathrm{C}$ lower than the $18^{\circ} \mathrm{C}$ optimal temperature fluctuation recommended by Wathes et al. (1983) more than two decades ago. Similarly, due to changing worldwide environmental climate and improvement in breeding livestock that could alter body metabolism in relation to the environment, more than a decade later, Harmon and Xin (1995) reported that the critical low temperature for a $109 \mathrm{~kg}$ pig is $11.1^{\circ} \mathrm{C}$ and its critical high temperature was $26.7^{\circ} \mathrm{C}$. Therefore, the temperature fluctuation that the animal can tolerate was $15.6^{\circ} \mathrm{C}$. Based on the above condition, the temperature fluctuation range in the EPH that we obtained, which is $15^{\circ} \mathrm{C}$ can already be considered almost adequate to provide comfort for the finishing pigs raised up to $107 \mathrm{~kg}$. On the other hand, the $\mathrm{CPH}$ also maintained a steady temperature range of around $11^{\circ} \mathrm{C}$. This indicated that it was largely influenced by the outside temperature It is also worth noting that the temperature difference between the upper and lower parts of the pig pens was relatively steady in the EPH at about $1^{\circ} \mathrm{C}$ (excluding the alley, 6th measured spot). In contrast, the deviation in the $\mathrm{CPH}$ was about $2^{\circ} \mathrm{C}$. The stable and minimal indoor temperature fluctuation in the EPH was beneficial to the pigs as they are homeothermic and have to maintain a relative constant temperature by adjusting their heat production. Therefore, the more stable the indoor temperature, there will be lesser stress. Geers et al. (1988) reported that if the pigs weight is less than $50 \mathrm{~kg}$, the air temperature within the pig pens has to be maintained at $17^{\circ} \mathrm{C}$ to $25^{\circ} \mathrm{C}$. This jibe with the findings of Harmon and Lawrence (1995) that a $23 \mathrm{~kg}$ pig will tolerate a critical temperature of not less than $21^{\circ} \mathrm{C}$. Our design for the EPH was able to maintain a narrow indoor temperature range within the pig pens at $17^{\circ} \mathrm{C}$ to $23^{\circ} \mathrm{C}$, which was more than enough to protect the animals from going beyond its critical temperature. However, when the animal has attained its maximum growth potential, the day and night temperature variation can be increased as long as it is within the allowed range. This theory was satisfied as the EPH showed almost no temperature fluctuation, whilst the $\mathrm{CPH}$ displayed a steep inclination between the upper and lower altitudes of the pens. This can be interpreted as a large influence of outdoor temperature due to poorly regulated airflow. Consequently, our EPH design satisfied the temperature range of 15.5 to $20^{\circ} \mathrm{C}$ that guarantees faster growth because of lesser heat loss and more feed intake of pigs as claimed by MWPS-8 (1988).

Airflow dynamics and pattern: The airflow velocity of the EPH during winter is shown in Table 2. The inflowing air was slightly warmed near the ceiling and moved downwards to both sides of the walls of the pens then towards the alley. Due to the minimum ventilation by the air fan duct attached to one side of the wall, the velocity of the inflowing air was 0.59 to $0.78 \mathrm{~m} / \mathrm{s}$ and the average air velocity in the lower area of the stall was $0.06 \mathrm{~m} / \mathrm{s}$. This indicates that there was no stagnant air from the different sites of measurement as shown in Figure 2 wherein there is continuous and uniform distribution of airflow. Our data on air velocity in the lower area obtained by our EPH design is almost similar that obtained by Grub et al. (1974) which is at least $0.08 \mathrm{~m} / \mathrm{s}$. He further claimed that this air velocity rating was already capable of liberating toxic gases from pig houses. Therefore, the $0.06 \mathrm{~m} / \mathrm{s}$ air velocity which we obtained considering its closeness to $0.08 \mathrm{~m} / \mathrm{s}$ may also be sufficient to liberate obnoxious gases which could improve the growth rate of the pigs and further demonstrated by a 6 $\mathrm{kg}$ advantage in bodyweight of the pigs during winter time. Moreover, Harmon and Lawrence (1995) reported that an inflowing air velocity of less than $0.15 \mathrm{~m} / \mathrm{s}$ can result to stress on small pigs and at less than $0.3 \mathrm{~m} / \mathrm{s}$ can be harmful to large pigs during winter. Unfortunately, no air movement could be measured $(0.00 \mathrm{~m} / \mathrm{s})$ in almost the lower parts of the front, middle and rear section of $\mathrm{CPH}$ as shown in Table 2. This is attributed to the fact that there was negligible amount of airflow in the air slot, which resulted to the adverse effect or inferior growth rate of the pigs reared under $\mathrm{CPH}$.

Based on the above observations, the environmental conditions of pigs reared under CPH are extremely poor since there is no airflow in the lower portion of the pen, which is the critical breathing space of the pig. MacDonald (2005) reported the importance of distribution and velocity are very important considerations in a ventilation system. He further established that the minimum ventilation rate for a $30-\mathrm{kg}$ pig is $650 \mathrm{ft}^{3} / \mathrm{m}$. Apparently, adjusting air slot to 


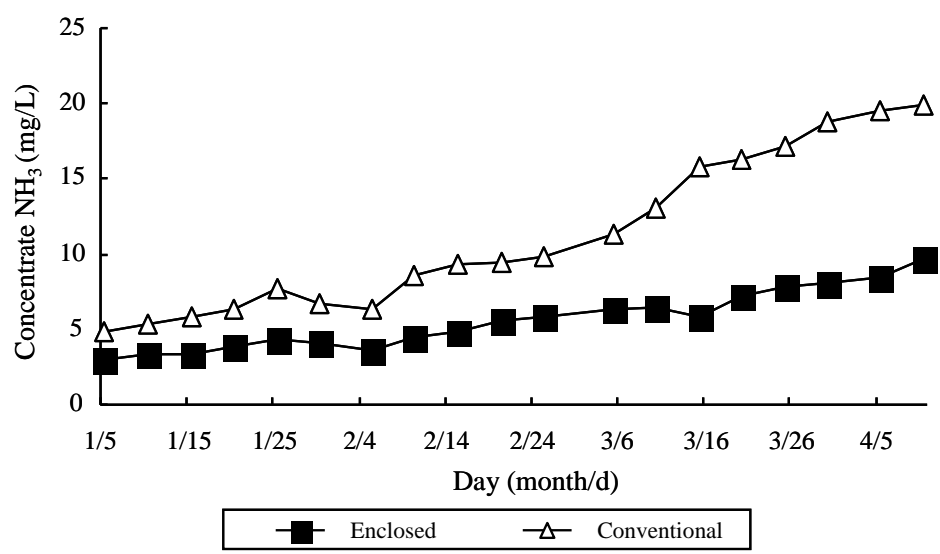

Figure 3. Periodic changes of $\mathrm{NH}_{3}$ concentration of the $\mathrm{EPH}$ and $\mathrm{CPH}$ during winter.

improve airflow and subsequently air velocity in the pens was demonstrated in this study.

$\mathrm{NH}_{3}$ emissions: An increasing indoor temperature can significantly result to higher concentration of $\mathrm{NH}_{3}$ as demonstrated in the correlation studies of Choi et al. (2005) between air pollutants and thermal environment factors in a confined pig house during winter. The periodic measurements of indoor $\mathrm{NH}_{3}$ emission during winter in both the $\mathrm{EPH}$ and $\mathrm{CPH}$ is shown in Figure 3. A maximum concentration of $19.7 \mathrm{mg} / \mathrm{L}$ was evident in the $\mathrm{CPH}$ whilst an expectedly lower level at $9.6 \mathrm{mg} / \mathrm{L}$ was recorded in the EPH. Both indoor emissions were lower than the allowed concentration of $20 \mathrm{mg} / \mathrm{L}$ (MWPS 32, 1990). However, there was a great variation in $\mathrm{NH}_{3}$ emission between summer and winter in the EPH (16 vs $9.6 \mathrm{mg} / \mathrm{L}$ ) whilst that in the CPH was minimal (17 vs $19.7 \mathrm{mg} / \mathrm{L}$ ). An important observation in the present study, was that the $\mathrm{NH}_{3}$ concentration during summer was lower compared to winter in the $\mathrm{CPH}$. Whether variation in metabolic production of $\mathrm{NH}_{3}$ by the animals due to season will be another subject of investigation in the future so that no adjustment would be done in the design of the EPH. Another investigation that will be done is whether degree of coldness or hotness of air can affect dilution or dissipation rate of $\mathrm{NH}_{3}$. Variations on the design and dimension of the $\mathrm{CPH}$ to include width of air duct will also be done to confirm the dilution potential of air inflow on the $\mathrm{NH}_{3}$ gas. Another relevant finding was the minimum ventilation rate during winter resulted to an $\mathrm{NH}_{3}$ level in the EPH, which is $49 \%$ lower than the $\mathrm{NH}_{3}$ emission from the CPH. Starting from February 4, the pigs in our study were already $60 \mathrm{~kg}$ and this is the peak of their metabolism rate, that can also result to an increase in emission of toxic gases. Proper ventilation during this period is therefore necessary. Barker et al. (1986) reported that $\mathrm{NH}_{3}$ concentration levels of pig houses with efficient liquefied excretion disposal systems were 10 to $20 \mathrm{mg} / \mathrm{L}$. The EPH in the present study provided a better environment for the pigs as $\mathrm{NH}_{3}$ level was low.

Growth and feed intake: As shown in Figure 4 pigs reared in the EPH were heavier by $6 \mathrm{~kg}$ than those pigs reared in the CPH during winter. In Table 4, the pigs in the EPH also consumed a significantly higher amount of feeds resulting likewise to a better weight gain than those pigs raised in the $\mathrm{CPH}$. A report of a study at the University of Missouri as cited by Harmon and Lawrence (1995) reported a marked improvement in pig performance reared in enclosed confinement facilities during winter which is in contrast to our result. Pigs raised in the EPH had better performance during summer. Apparently, this is attributed to the humid summer condition in Korea, however,

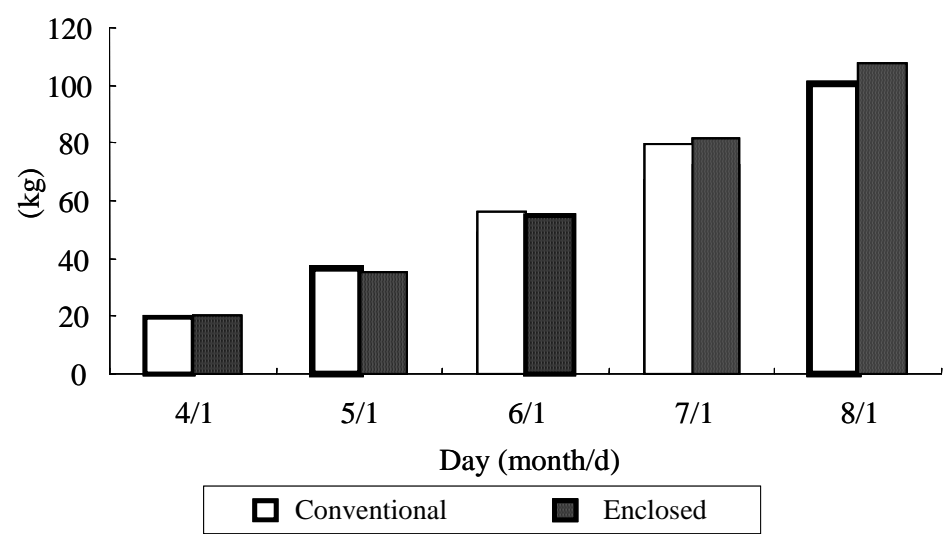

Figure 4. Monthly weight of the pigs raised in the $\mathrm{CPH}$ and $\mathrm{EPH}$ during winter. 


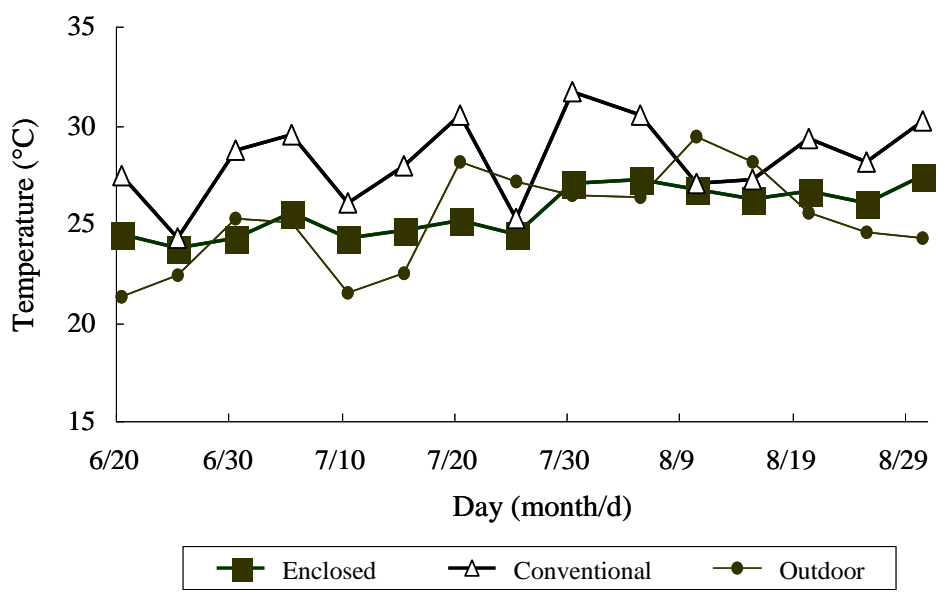

Figure 5. Periodic changes of air temperature of the $\mathrm{EPH}, \mathrm{CPH}$ and the outdoor temperature during summer.

evidence on its direct role should be the subject of investigation in the future. Finally, it was well demonstrated in the present study that air flow dynamics was better in EPH because of the critical role of the inlet (Figure 8) as compared to the $\mathrm{CPH}$ without the inlet (Figure 9).

\section{Summer setting}

Temperature dynamics: Ventilation system during summer should be designed to maintain heat balance in contrast to winter ventilation wherein moisture balance should be maintained. Likewise, during summer an adequate heat removal by the ventilation system is crucial as suggested by Schauberger et al. (2000). The benefit of the ventilation system of the EPH in maintaining homeothermic heat was demonstrated in this study when it recorded a minimal indoor temperature fluctuation range of only $7^{\circ} \mathrm{C}$ as shown in Figure 5. This minimal variation was consistent when taken from the different measuring points in all the individual pig pens. Although the outside temperature varied greatly from 23 to $30.5^{\circ} \mathrm{C}$, it had a lesser deviation when compared to the $\mathrm{EPH}$ thus minimizing stress for growing pigs. On the other hand, the $\mathrm{CPH}$ displayed a sharp increase and decline in temperature and almost approximated the uptrends and downtrends of the outdoor temperature. Moreover, it had a higher difference than that of The EPH. This dynamics on the indoor temperature of the $\mathrm{CPH}$ during summer can result to heat stress and adversely affect growth performance of animals. During the past, EPH was not popular because of the difficulty to match indoor temperature and body heat emission of pigs to achieve heat balance. The EPH design in the present study was equipped with the needed materials and proper orientation of the ventilation system, as shown in Figure 1. The comfort of the animals was expected as the indoor temperature fluctuation during summer was reduced with a range of 23.8 to $27.5^{\circ} \mathrm{C}$ only. This observation was based on the report of Spillman and Hinkle (1971) that when a $70-\mathrm{kg}$ pig is reared at an indoor temperature of 22 to $27^{\circ} \mathrm{C}$, no heat loss is generated resulting to better growth efficiency which is reflected in the subsequent table of the present study.

Airflow dynamics and pattern: A high velocity during summer can make pigs comfortable due to reduced temperature. Our design for EPH in the present study is appropriate for Korean climate as it was capable of attaining a maximum ventilation level of $240,000 \mathrm{~m}^{3} / \mathrm{h}$. The air speed distribution from the walls of both sides of the pens and consequently emitted by the air fan duct is presented in Table 3. The velocity of the air that enters from the air slots on both sides of the stall was slightly faster at

Table 3. Air velocity distribution of the EPH and CPH during summer $(\mathrm{m} / \mathrm{s})$

\begin{tabular}{|c|c|c|c|c|c|c|c|c|c|}
\hline \multirow{2}{*}{ Location } & \multicolumn{3}{|c|}{ Front section } & \multicolumn{3}{|c|}{ Middle section } & \multicolumn{3}{|c|}{ Rear section } \\
\hline & Left & Alley & Right & Left & Alley & Right & Left & Alley & Right \\
\hline \multicolumn{10}{|l|}{$\overline{\mathrm{EPH}}$} \\
\hline Upper & 2.59 & 0.03 & 2.61 & 2.73 & 0.04 & 2.62 & 2.48 & 0.04 & 2.49 \\
\hline Middle & 1.77 & 0.04 & 1.53 & 1.82 & 0.04 & 1.48 & 1.65 & 0.03 & 1.47 \\
\hline Lower & 0.29 & 0.10 & 0.34 & 0.31 & 0.08 & 0.29 & 0.31 & 0.08 & 0.28 \\
\hline \multicolumn{10}{|l|}{$\mathrm{CPH}$} \\
\hline Upper & 1.16 & 1.43 & 1.78 & 1.05 & 1.21 & 1.48 & 1.32 & 1.25 & 1.33 \\
\hline Middle & 0.52 & 1.36 & 0.67 & 0.43 & 1.27 & 0.57 & 0.61 & 1.38 & 0.54 \\
\hline Lower & 0.14 & 0.23 & 0.16 & 0.07 & 0.25 & 0.12 & 0.09 & 0.32 & 0.13 \\
\hline
\end{tabular}

Summer* Mean \pm STD: $0.23 \pm 0.10 \mathrm{~m} / \mathrm{s}$. Winter* Mean \pm STD: $0.01 \pm 0.01 \mathrm{~m} / \mathrm{s}$. 
Table 4. Gain in weight and feed intake of pig reared under EPH and $\mathrm{CPH}$ during winter and summer

\begin{tabular}{ccc}
\hline House type & Weight gain $(\mathrm{kg})$ & Feed intake $(\mathrm{kg})$ \\
\hline Winter* & & \\
CPH & $664 \pm 11.6^{\mathrm{b}}$ & $1,321 \pm 17.4^{\mathrm{b}}$ \\
EPH & $869 \pm 13.8^{\mathrm{a}}$ & $1.498 \pm 15.2^{\mathrm{a}}$ \\
Summer* & & \\
CPH & $671 \pm 12.7^{\mathrm{b}}$ & $1,298 \pm 16.7^{\mathrm{b}}$ \\
EPH & $894 \pm 15.6^{\mathrm{a}}$ & $1.521 \pm 13.6^{\mathrm{a}}$ \\
\hline
\end{tabular}

Winter* a, b Values bearing different superscript in a row differ significantly, $(\mathrm{p}<0.05)$.

Summer* a, b Values bearing different superscript in a row differ significantly, $(\mathrm{p}<0.05)$.

the center of the stall but generally stable and uniformly evident around the lower areas of the pens (Figure 10). The airflow direction and pattern is presented to serve as a guide on what adverse or beneficial effects it can bring to the animals. This is because varying speeds can reduce indoor temperature and at the same time create cold stress for the animals when it passes through its skin. Therefore, there should be a ideal matching between indoor temperature and air speed. In our EPH design, our recorded air velocity at $0.23 \mathrm{~m} / \mathrm{s}$ was able to satisfy the optimum air velocity in the confinement area as well as breathing space of the pigs (nose level) set by Sainsbury (1995) of 0.13 to $0.18 \mathrm{~m} / \mathrm{s}$ compared to our record which is $0.23 \mathrm{~m} / \mathrm{s}$. It also complied with the minimum air velocity set by Grub et al. (1974) at $0.08 \mathrm{~m} / \mathrm{s}$ to effectively expel toxic gases from the pig house.

Conversely, just like the winter setting, there was practically no air movement again in the $\mathrm{CPH}$, particularly in the lower area as indicated by their air speed and airflow direction (Table 3, Figure 11). Ironically, there was faster air speed in the alley, which is not within the direct breathing space for the growing-finishing hogs and is therefore a useless airflow (Table 3). Therefore, Korean livestock farmers who are adopting the $\mathrm{CPH}$, should recognize that this defect in their indoor airflow speed can affect growth performance of their animals.

Although the speed of air that entered through the air slots was lower than what is deemed optional by MWPS 32 (1990), which was $5 \mathrm{~m} / \mathrm{s}$ for proper ventilation, it was still effective as air flow was rotating throughout the pig pens for both the EPH and CPH (Figures 10 and 11). During summer, the airflow characteristics in the EPH is described such that it proceeded downward after gaining entry into the left air slot. The downward trend continues until it reaches the slat level then bounced back following a counterclockwise motion. After it rises to a height of around 2 meters it returns back to the slat level then follows the same counterclockwise motion or a part of the airflow current can move to the right side of the building and converge with an airflow pattern that is maintaining a circular pattern in a clockwise manner. This is made possible due to the entry of the airflow from the opposite direction. The maximum height level attained is also the same with the left portion of the building and therefore assumed a balanced symmetry of circles in perpetual motion. On the other hand, activation of airflow direction of the $\mathrm{CPH}$ during summer originated from the pit exhaust fan of both sides of the building and converged towards the alley after passing the breathing space of the pigs. The airflow of the left portion of the building follows a counterclockwise motion with a maximum height of 2 meters whilst that of the right portion of the building assumed a counterclockwise flow. We also noted that these airflow directions and patterns are similar with those in the winter setting, which can be influenced by the housing systems particularly the dimensions. The only difference detected was that the faster airspeed was very distinct during summer. Therefore, airspeed can be season dependent relative to different housing systems. Presently, there is a dearth of information on the airflow characteristics in pig houses and this exhaustive description of the airflow direction and pattern which was made possible due to pioneering identification of the 27 measuring spots in the two types of pig houses will be a useful information to livestock farmers in formulating strategies for prevention of respiratory problems. This is very important as the higher the indoor temperature in pig houses, the greater will be the influence of air velocity on the living comfort and growth of pigs.

$\mathrm{NH}_{3}$ emission: The present study noted that even when the $\mathrm{CPH}$ was exposed to outside air, toxic gases within the living quarters were not expelled effectively and showed similar levels to that of the EPH. Usually, a low level of air exchange will result to a higher humidity and consequently higher concentration of noxious gases such as $\mathrm{NH}_{3}$ and $\mathrm{CO}_{2}$. Accordingly, minor modification preferably on the location or the width of the EPH to maximize air inflow to air outflow will be tested. Furthermore, another intensive study in the EPH, will be done with emphasis on the air flow current dynamics or expulsion of gas even if they are not concentrated on both the upper and lower parts of the pens.

The comparative concentration levels of $\mathrm{NH}_{3}$ in both the $\mathrm{EPH}$ and $\mathrm{CPH}$ during summer is shown in Figure 6. In the $\mathrm{CPH}$, concentration level was stable at less than $17 \mathrm{mg} / \mathrm{L}$ towards the market age of the pigs while the EPH was less concentrated and more stable at $16 \mathrm{mg} / \mathrm{L}$, both figures were lower than the tolerable level of $20 \mathrm{mg} / \mathrm{L}$ (MWPS 32, 1990). The liquid manure pit system of both houses was also a contributory factor in reducing the $\mathrm{NH}_{3}$ emission because of the reaction: $\mathrm{NH}_{3}+\mathrm{H}_{2} \mathrm{O}=\mathrm{NH}_{3} \mathrm{OH}$, thus diluting ammonia to ammonia hydroxide which is a less obnoxious compound. It is advised further that manure should be scraped and not left 


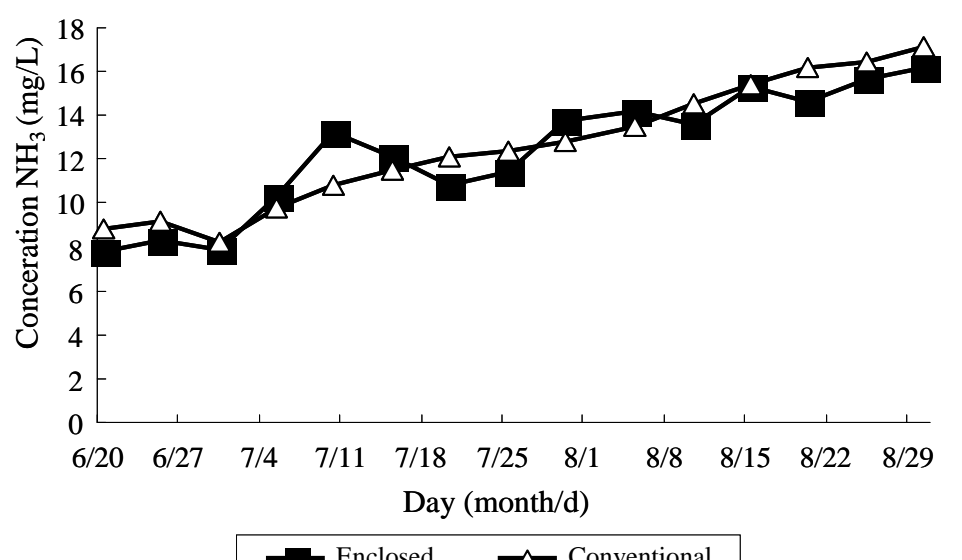

Figure 6. Periodic changes of $\mathrm{NH}_{3}$ concentration of the $\mathrm{EPH}$ and $\mathrm{CPH}$ during summer.

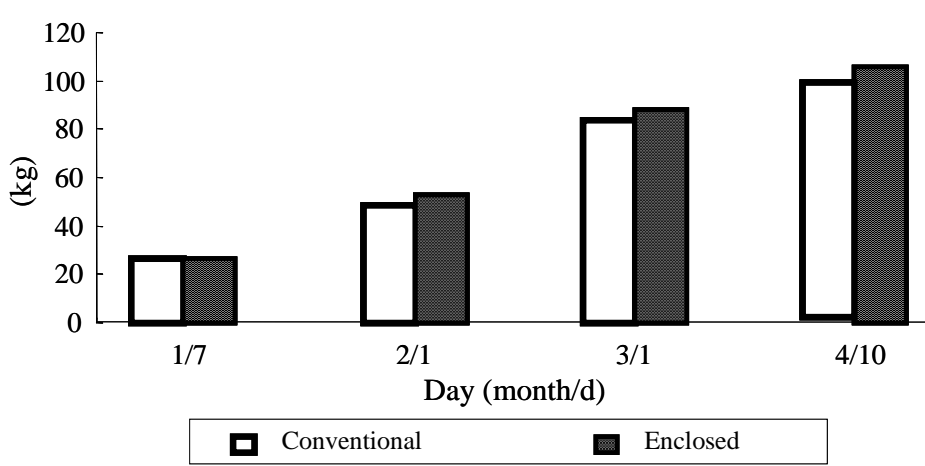

Figure 7. Monthly weight of the pigs raised in the $\mathrm{CPH}$ and $\mathrm{EPH}$ during summer.

behind on the slats as a higher emission level of $\mathrm{NH}_{3}$ is expected when they become dry. Based on this result, we can conclude that this additional EPH method of modifying indoor environment will enable its widescale adoption by Korean livestock farmers.

Growth and feed intake: As shown in Figure 7, Table 4, the final weight of the pigs reared in the EPH were heavier by $7 \mathrm{~kg}$ compared to the pigs reared under the CPH. Consequently, there was a significant gain in weight and feed intake of pigs raised in the EPH over those pigs reared in the CPH. This is an indication that the pigs in the EPH were afforded a better environment and was translated into

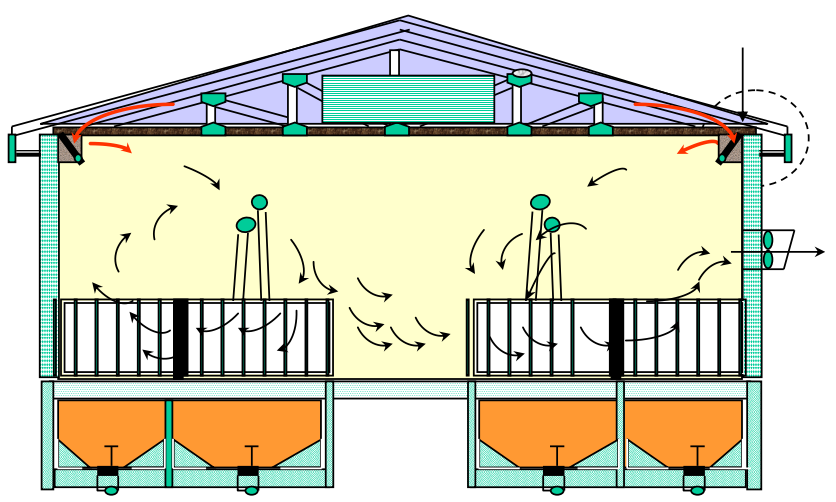

Figure 8. Schematic of airflow direction and pattern in the EPH during winter. improved performance in their growth parameters. This also implied that there was lesser stress on their part which is an indication of an appropriate environmental condition. The indoor temperature, which was not largely influenced by the outdoor temperature in the EPH was also a major contributory factor. This is because when temperature drops, more energy is needed to satisfy the heat requirement of the animal. Although feed intake is increased during this period, its maintenance requirement will also increase faster leaving less energy for weight gain and therefore the growth of the animal is adversely affected. Subsequently, to supply the needed energy to sustain normal growth, an effective temperature for a homeothermic animal like the pig is needed. And this is possible if the thermoneutral zone

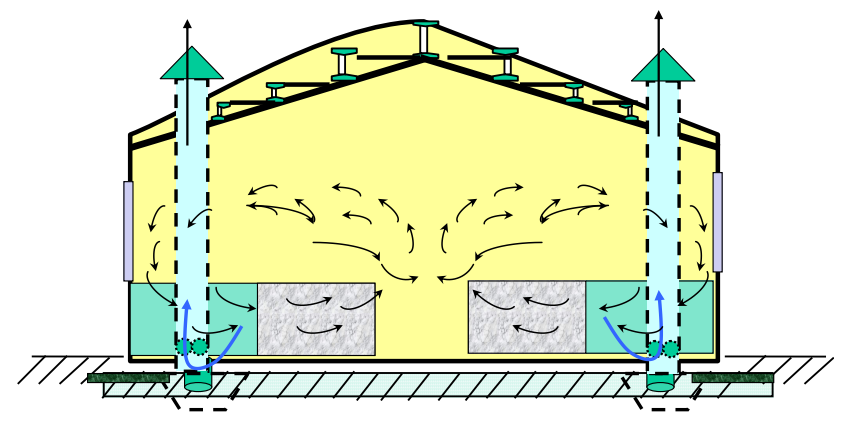

Figure 9. Schematic of airflow direction and pattern in the $\mathrm{CPH}$ during winter. 


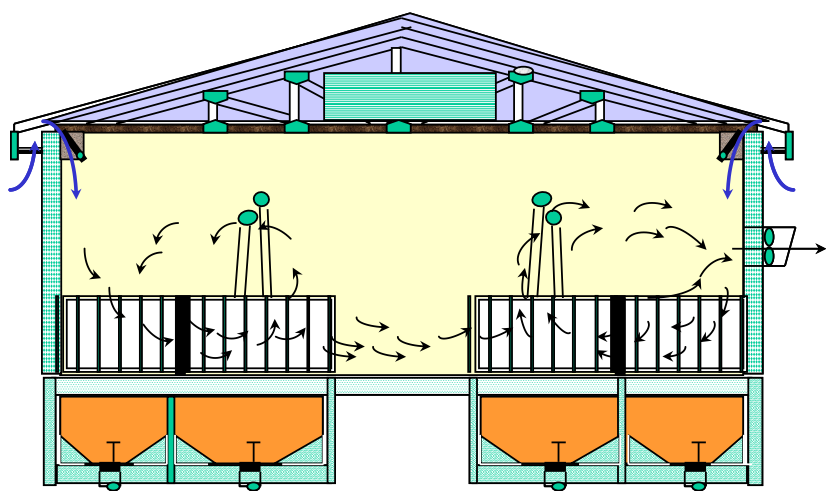

Figure 10. Schematic of airflow direction and pattern in the EPH during summer.

(TNZ) of the pig is maintained. In the study, there was a narrower fluctuation of the temperature in the EPH than the $\mathrm{CPH}$, therefore, better TNZ was attained by the pigs raised under forced ventilation or EPH.

\section{IMPLICATIONS}

Air distribution and velocity are very important considerations in a ventilation system and usually the major cost of this is the air distribution inlet system. The effect will therefore be uneven summer airflow due to undersized air inlet. Non-uniform location due to defective building design and obstructions will result to stale and hot spots. In our present study, however, there were effective airflow patterns especially in the breathing space of pigs during winter and summer for our EPH design. The CPH had also a satisfactory airflow during winter but not on summer. This requires follow up investigation and determine if airflow can be improved by remodeling the suction capacity of the pit exhaust fan. Fans usually do not suck air evenly due to excess spacing causing non-unform distribution of air. Pigs have minimum ventilation requirement according to age. If this is not set to provide the desired airflow, problems will arise. Too high an exhaust flow wastes energy and dries air out resulting to heat shortage; too low exhaust airflow rate and air quality suffers. In the present study, $\mathrm{NH}_{3}$ level which is an indicator for air quality was lower than the tolerable level. The benefit of good airflow and consequently proper ventilation was achieved in our EPH because of automatic 5-stage operating capacities of the mechanical ventilation that we used. The automatic adjustment of ventilation rate in the present study had a minimum of $5 \%$ to a maximum of 95\%. Therefore, EPH designs should also be complemented with appropriate ventilating equipment if living environment of pigs and their growth performance are to be further improved in Korea. The EPH designs including dimensions, in the present study, satisfied the desired airflow characteristics and therefore can be considered for adoption. Finally, efforts to match inlet designs and width

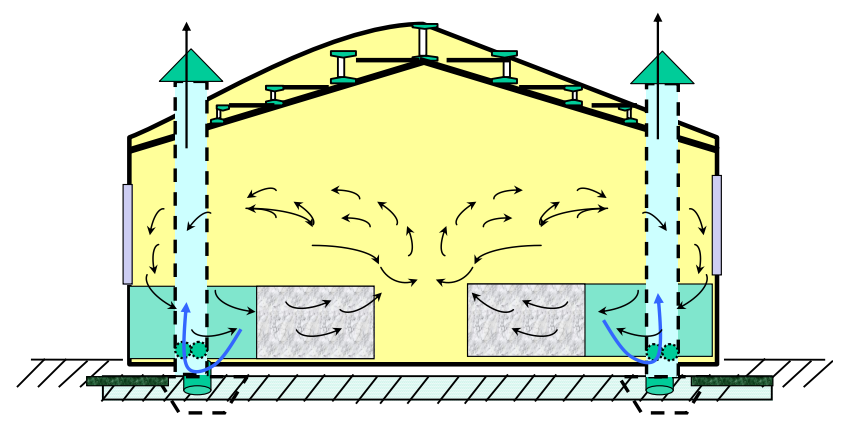

Figure 11. Schematic of airflow direction and pattern in the $\mathrm{CPH}$ during summer.

as well as remodeling to sustain good airflow is underway.

\section{REFERENCES}

Barker, J., S Curtis, O. Hogsett and F. Humenik. 1986. Safety in swine production systems. Pork Industry Handbook. p. 104.

Bond, T. E., H. Heitman, Jr. and C. F. Kelly. 1965. Effects of increased air velocities on heat and moisture loss and growth of swine. Trans. ASAE. 8:167-169.

Brugger, M. F. and L. A. Brooks. 1977. Ventilation of dairy and other livestock building-design, operation and equipment. Univ. Wis. Ext. Bull. A2812.

Choi, H. L., K. Y. Kim and H. Kim. 2005. Correlation of air pollutants and thermal environment factors in a confined pig house in winter. Asian-Aust. J. Anim. Sci. 18:574-579.

Choi, H. L., J. I. Song and H. K. Ahn. 2000. Field survey of structural and environmental characteristics of pig houses in the southern provinces in Korea. J. Lives. Hous. Env. 6:1-14.

Curtis, S. E. 1983. Environmental managment in animal agriculture. University Extension Bulletin. Livestock Industry Facilities and Environment Ames, Iowa State University.

Esmay, M. L. 1978. Principles of Animal Environment. AVI Publishing Company, Inc.

Geers, R., E. Vranken, V. Goedlseels, D. Berkmans and F. Maes. 1988. Air temperature related behavioural problems and mortality rate of pigs. Livestock Environment III. ASAE Publication. 1-88, 343-348.

Grub, W., E. P. Foerster and L. F. Tribble. 1974. Swine building air contaminant control with pit ventilation. Presented at the 1974 Winter Meeting. Paper No. 74-4532. ASAE, St. Joseph, MI, USA.

Harmon, J. D. and J. Lawrence. 1995. Open vs enclosed swine finishing: making the decision. University Extension Bulletin. Livestock Industry Facilities and Environment Ames, Iowa State University.

Harmon, J. D. and H. Xin. 1995. Environmental guidelines for confinement swine housing. University Extension Bulletin. Livestock Industry Facilities and Environment Ames, Iowa State University.

MacDonald, R. 2005. Indoor air quality and ventilating systems in pig barns. Technical Article.http//www.engormix.com.

MWPS 8. 1988. Swine housing and equipment handbook. 4th Edition. Midwest Plan Service, Ames, Iowa, USA.

MWPS 32. 1990. Mechanical ventilating systems for livestock housing. First Edition. Midwest Plan Service, Ames, Iowa, 
USA.

SAS Institute Inc. 1991. SAS Language and Procedures: Version 6. First Edition . SAS institute Inc. Cary, North Carolina, USA.

Sainsbury, D. W. B. 1995. Pig health, environment and housing.
In: The Health of Pigs (Ed. J. R. Hill and D. W. B. Sainsbury) Longmon Singapore Publishers (Pte) Ltd., Singapore. p. 69.

Schauberger, G., M. Piringer and E. Petz. 2000. Dynamic model of the indoor climate inside livestock buildings: A case study for fattening pigs. Conference Paper. First International Swine Housing Conference. Iowa, October, 2000.
Spillman, C. K. and C. N. Hinkle. 1971. Conduction heat transfer from swine to controlled temperature floors. Trans. ASAE 14: 301-303.

Yoo, J. E., J. Y. Joo, S. C. Kim, C. S. Park, D. I. Chang, H. H. Chang and Y. I. Lim. 1998. Development of Korean pighousing models for the optimum control of environmental systems. J. Lives. Hous. Env. 4:113-126.

Wathes, C. M., K. Howard, C. D. R. Jones and A. J. F. Webster. 1983. Ventilation, air hygiene and animal health. Vet. Rec. 113: 554-559. 